\title{
CAREERS
}

WILD WORLD Preserving the habitat of bears and wolverines $\mathbf{p . 4 2 1}$
BLOG Personal stories and careers counsel http://blogs.nature.com/naturejobs
NATUREJOBS For the latest career listings and advice www.naturejobs.com

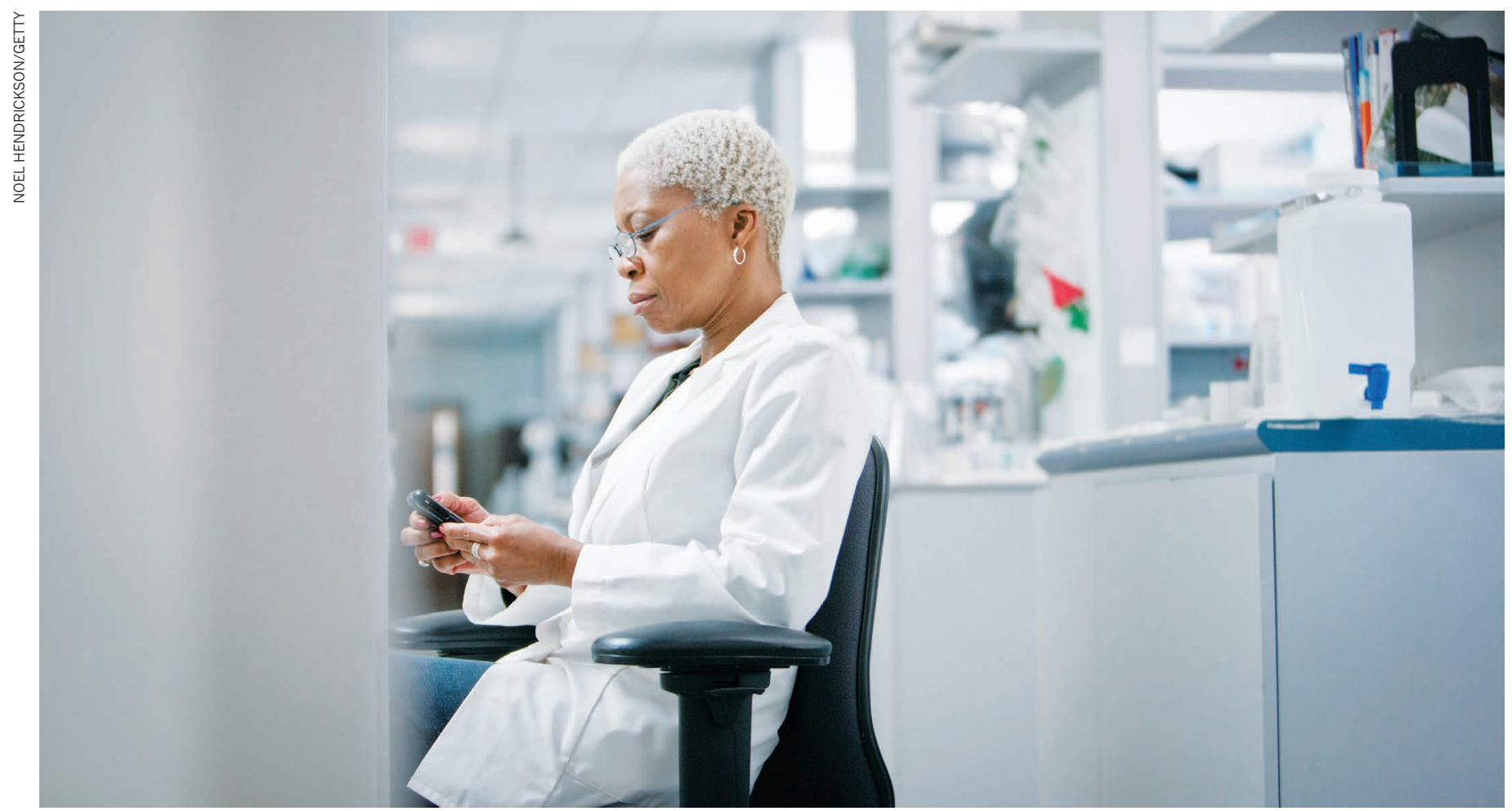

Some researchers are juggling multiple short-term jobs as the gig economy begins to influence the scientific sector.

FLEXIBLE WORKING

\section{Science in the gig economy}

Will the future of research rely on independent workers who perform short-term jobs? Labour researchers and freelance scientists share their views.

$\mathrm{T}$ The global gig economy has influenced industries from taxi driving to software engineering. With the rise of websites and apps such as Uber, TaskRabbit and Upwork, more workers than ever are selling short-term services to many clients rather than holding down single full-time jobs.

People with scientific training are adopting these practices as well, either by offering services on sites such as Upwork or finding projects through their previous academic networks. About 3,200 freelancers, most with backgrounds in the life or physical sciences, sell services such as statistical review and literature searches through the online platform Kolabtree.com, which is based in London and started in 2015. And in May, LabMate in Boston,
Massachusetts, launched its site LabMate.us to match researchers with consulting gigs and full-time jobs at biopharmaceutical companies; about 200 scientists have registered so far.

Although researchers have always taken on jobs with finite timeframes, such as postdocs and adjunct teaching, many of the projects completed through gig-economy platforms are shorter and performed remotely. So will the gig economy transform the scientific enterprise? Nature asked freelance scientists and labour researchers for their views.

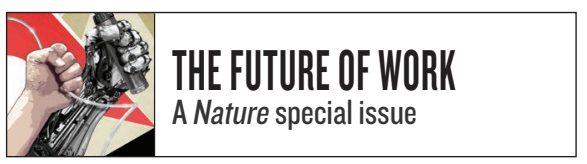

ANNE THESSEN

\section{The independent data scientist}

Founder, The Data Detektiv, Waltham, Massachusetts, and research scholar at a virtual organization for independent researchers.

I'm an oceanographer by training. I spent at least two years applying for academic jobs, and there were about 200 applicants for each one. While I was doing this, people I knew from my research career asked me to work on their 
projects. My first client was the Encyclopedia of Life (eol.org), a website that builds a page for every species; I was doing programming for content acquisition. A colleague at the University of Maryland Center for Environmental Science's Horn Point Laboratory in Cambridge, Maryland, asked if I would help populate a database of oceanographic and hydrocarbon measurements. The pieces were starting to come together - I could be an independent scientist.

The gig economy enables you to keep yourself afloat while other things have time to mature. When I started as an independent scientist, I also drove for Lyft, an Uber competitor, for about a week. I had quite a bit of freelance work on science projects, but I still wanted to feel safe, so I decided to pick up a little extra work. After a week, I realized I didn't need it and didn't have time to do it. But it gives you a safety net; you have in the back of your mind that you could easily do something else in your down time.

There are lots of scientists in the wilderness - that point where you are tired of doing postdocs and you question what you're doing. The gig economy can be one way to find a path, by providing an income stream while you figure stuff out. It can help you realize what marketable skills you have. It can give you time to mourn the loss of a job in academia that you thought you were going to have but that never really existed. And it helps to expand your network into places that would be interested in your skill set, such as the technology community. Eventually, you realize you can leave academia without leaving research.

Scientists don't need universities any more. In the Boston area, the start-up community is driving the need for resources that can be consumed and discarded on very short time scales. You can rent office space, lab space and equipment; you can pay for processing time on a server; you can hire a car or boat to take you to sampling locations.

My hopeful view of the future is that scientists will have more freedom, and the gig economy is one way to make that happen.

\section{LAWRENCE KATZ The labour economist}

Economist, Harvard University, Cambridge, Massachusetts.

Alan Krueger of Princeton University in New Jersey and I estimated that as of autumn 2015, about $0.5 \%$ of the US workforce had their main or secondary job in the online gig economy. If you expand to independent contractors, freelancers, on-call workers, temporary-help agency workers or people who are contracted out in their main job, it's about $16 \%$ of the US workforce - and it was about $10 \%$ a decade ago. So it's grown very rapidly.

For most of what academic scientists do, there hasn't been that big of a change. But in some areas, such as data science and technology work, the gig economy is having a much greater effect. For computer and mathematical professions, about $22 \%$ of workers are in alternative work arrangements. As big data has grown, greater numbers of large teams are being assembled. You could have freelance programmers working on a project in any location, doing statistical analysis or providing code.

Potentially, we haven't realized all the benefits of the greater availability of talent anywhere in the world to help with tasks such

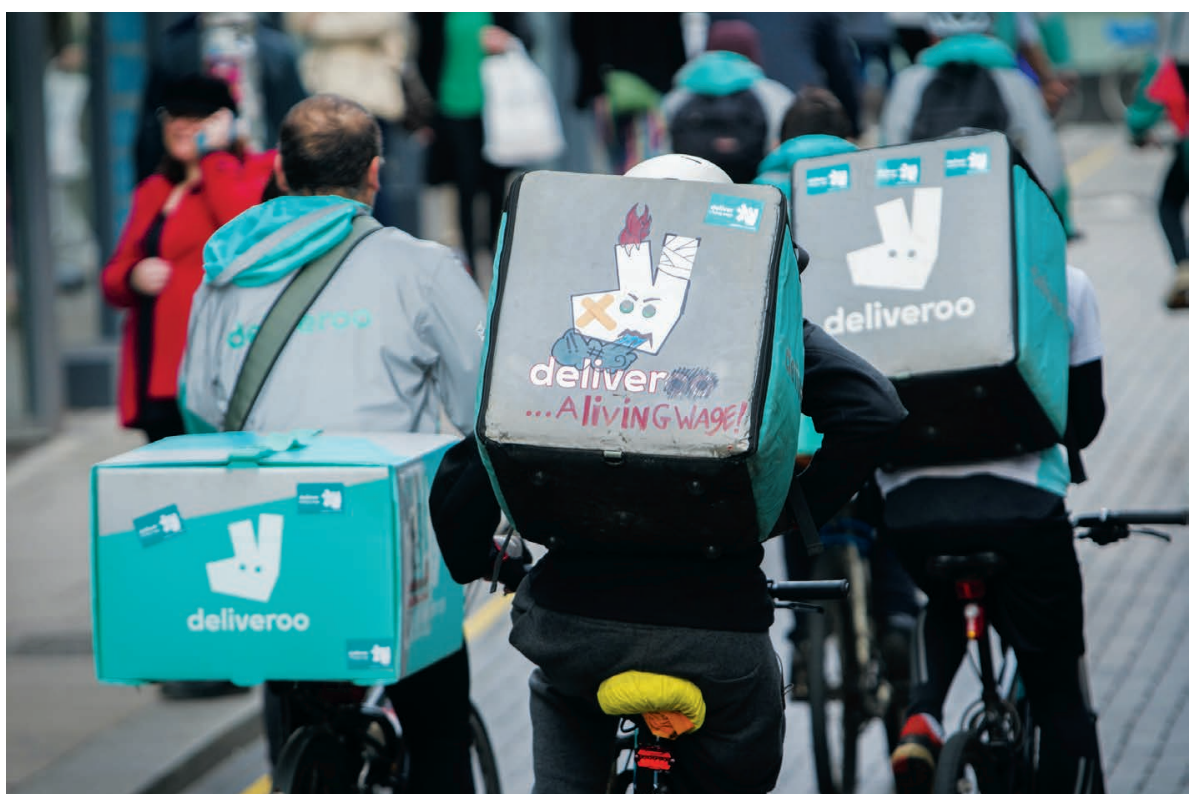

Not all gigs are created equal; here, Deliveroo workers attend a protest for higher wages.

as inputting the same data multiple times to check errors. Anything that lowers the cost of others verifying research may be helpful in the reproducibility of science.

But the rights of freelance scientists will increasingly become issues. What happens if you have an illness or injury? You're not covered by workers' compensation. New forms of benefits could operate like workers' compensation or unemployment insurance, with independent workers paying into a fund that they could draw from in down times. We need new institutions.

\section{URSULA HUWS The sociology researcher}

\author{
Social scientist, University of \\ Hertfordshire, Hatfield, UK.
}

In 2015, the Foundation for European Progressive Studies and UNI Europa, the Brusselsbased European services workers' union, invited me to do research on crowd work. We focused on paid work that is managed through online platforms such as Upwork, Clickworker, Uber and TaskRabbit. We surveyed approximately 2,000 working-age adults online in each of the United Kingdom, Germany, the Netherlands, Austria and Sweden. Very crudely, 1 person in 40 is getting more than half of their income from online crowd-work platforms.

A lot of online-economy practices are spreading into conventional employment. Academic jobs are looking more like gigeconomy jobs with the use of performance indicators and student surveys. On the site RateMyProfessors.com, for example, students score academics on their teaching skills and often make highly personal remarks. University-run student surveys increasingly feed into the appraisal process - if a course gets consistently low ratings, that has bad implications for the instructor. People are given targets to bring in external funding, and failing to meet them could put their careers in jeopardy. You have to spend more and more time begging and bragging, saying how wonderful you are and asking for money.

Serious research careers have been affected by 'projectification'. You get a finite project, two or three years. More and more teaching staff are employed on casual short-term contracts. Young researchers increasingly have fragmented careers, with poor work-life balance and career prospects. This constant need to pitch and the sense of being only as good as your last project - those are absolutely common to the gig economy and to academic labour.

Routine aspects of research, such as categorization and database verification, are being 
outsourced. In the social sciences, there's an enormous use of online platforms that are generally regarded as part of the gig economy, such as Amazon Mechanical Turk and Clickworker, which draw on a global labour force to carry out micro-tasks. A typical project would be: are people who are considered more attractive more likely to get hired? You might put photographs online and ask 'click workers' to grade attractiveness; in the next stage, you ask potential employers if they would employ this person. These workers not only fill in questionnaires but also do scientific tasks such as coding data, sorting and counting, which would previously have been done by research assistants or graduate students.

CALINE KOH-TAN
The freelance
science consultant

Freelance scientist, Singapore.

My $\mathrm{PhD}$ was in cardiovascular genetics at the University of Glasgow, UK. My first postdoc was mostly cardiovascular research, and the next was in veterinary sciences. Towards the end of my second postdoc, my husband and I decided to move back to my birth nation of Singapore. I thought: 'Why not see if I can work from home?'

I went to Upwork, a platform that allows freelancers to look for jobs. I did academicproofreading projects and other types of work. One client was a medical practitioner in the United States who was thinking of setting up a laboratory to test for diseases. He wanted advice on methods, tests and anything involved with running a lab,
"Regardless of the job, the way I do things is still the way I would do them as a scientist." such as reagents. Another client was a family member of a person with cancer who wanted to understand chemotherapy; I wrote a report explaining how it works and what factors influence the effectiveness of a particular drug. I have an active project as a freelance genomics consultant for Omic, a software start-up in Seattle, Washington. For instance, if they find two genomics databases, they might ask which one I recommend.

I also put data mining and biostatisticalanalysis skills on my profile. But about half of the job invitations so far have been from students looking for someone to do their class assignments. I will not accept those jobs.

My current rate is US\$30 an hour, but that is flexible - I work about 10-30 hours per week. My rate is lower than what I would make as a staff scientist or postdoc, but I consider it acceptable because I work less, have lower stress levels and fewer responsibilities, and do not have to constantly think about work during my non-working hours.

I miss the lab. But I do not see freelancing as losing out, because I still get to read the most up-to-date research. At the end of the day, regardless of the job, the way I do things is still the way I would do them as a scientist.

\section{CECILEMENARD The part-time freelancer}

Independent land-surface modeller; research associate, University of Edinburgh, UK; and member of a small virtual research organization for freelance scientists.

The common denominator between all the freelance scientists I know is location. We want to choose, geographically, where we're going to work. At some point, you don't want to move any more.

I lived in the United Kingdom for 15 years, did a postdoc there and went to Finland for another. Eventually, I wanted to be back home. I work in snow and vegetation research; it's a very small research field in Britain, and I couldn't find a job. You can register as a freelancer for tax purposes online (go.nature.com $/ 2 \mathrm{kamsoz}$ ) in five minutes. I told professors and a reader that I had registered, and one employed me as a consultant to run land-surface simulations.

There are two sides to being a freelance scientist. One is being a consultant providing services to someone. The other is being an independent researcher; you're not part of an organization, but you can perform research.

In some fields, collaboration with research organizations and universities will be imperative for freelancers to have access to instrumentation. For my work, I sometimes need a supercomputer. That's when collaboration is important; I've used the supercomputer of colleagues in England. For people who need to work in a lab, you may be able to go to one of your partners' labs.

I love the freedom. But for other people, it may be too stressful. A regular income is not guaranteed, and it is a risk if you want to do it full-time. I was fully freelance for one year. Now I'm working three days a week as a research associate at the University of Edinburgh on a project to reduce uncertainties in snow models; it gives me two days for my freelance work. It's a good safety net to have a part-time job.

\section{INTERVIEWS BY ROBERTA KWOK}

These interviews have been edited for length and clarity.

\section{TRADE TALK Habitat helper}

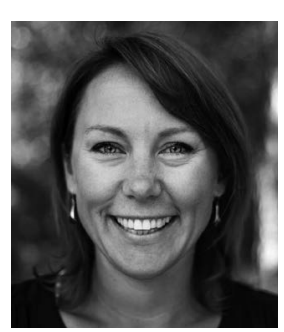

As a conservation scientist with the Yellowstone to Yukon Conservation Initiative (Y2Y), a joint CanadaUS non-profit organization that creates and protects wildlife habitats, Aerin Jacob has her dream job - protecting ecosystems, developing policy and helping people to coexist with wild animals.

\section{Why do you love your work?}

I've found a home for my personal values: protecting the environment, establishing connections between the health of ecosystems and of humans, and sharing our research results with the public and policymakers. In a typical week I might design plans to protect caribou habitat and set up camera traps to learn which animals inhabit the Y2Y region.

\section{How does it differ from an academic post?} There's more collaboration - it's more 'our' research than it is 'my' research. Things I used to do on the side are now integral parts of my job, including connecting with policymakers and journalists about our research.

\section{Why did you leave academia?}

I realized that it wasn't right for me. I was once told to cut down on the service, policy and outreach parts of my work because it looked weird on my CV. Now I don't have to do that.

\section{How did you land your job?}

I had experience presenting my research at public events and on the radio, as well as in science policy through several projects, including a programme based at McGill University in Montreal, Canada, that researches low-carbon policy options. I also organized almost 2,000 young researchers to lobby the Canadian government to use science in environmental decision-making.

Do you see your position as long-term? Yes. I have lots of ideas, such as developing a citizen-science project in which people collect data on wildlife movement, or working with isolated communities and industry to work out how to generate renewable energy while reducing negative effects on nature and protecting regional habitats. This job will never get stale.

\section{INTERVIEW BY SARAH BOON}

This interview was edited for length and clarity. 